\title{
MASS LOSS OF FOUR COMMERCIALLY AVAILABLE HEAT-POLYMERIZED ACRYLIC RESINS AFTER TOOTHBRUSHING WITH THREE DIFFERENT DENTIFRICES
}

\author{
Karina M. FREITAS-PONTES ${ }^{1}$, Cláudia H. SILVA-LOVATO² ${ }^{2}$ Helena F. O. PARANHOS ${ }^{3}$
}

\author{
1- DDS, MSc, PhD, Graduate Student, Department of Dental Materials and Prosthodontics, Dental School of Ribeirão Preto, University of São Paulo, \\ Ribeirão Preto, SP, Brazil. \\ 2- DDS, MSc, PhD, Professor, Department of Dental Materials and Prosthodontics, Dental School of Ribeirão Preto, University of São Paulo, Ribeirão \\ Preto, SP, Brazil. \\ 3- DDS, MSc, PhD, Associate Professor, Department of Dental Materials and Prosthodontics, Dental School of Ribeirão Preto, University of São \\ Paulo, Ribeirão Preto, SP, Brazil.
}

Corresponding address: Dra. Karina Matthes de Freitas-Pontes - Avenida do Café, s/n - Monte Alegre - 14040-904 - Ribeirão Preto - SP - Brasil Phone: +55-16-3602-4031- Fax: +55-16-3602-4780- e-mail: kamatthes@yahoo.com.br

Received: March 31, 2008 - Modification: August 31, 2008 - Accepted: September 16, 2008

\begin{abstract}
$T_{\text {he }}$

he association between a toothbrush and a dentifrice is the most used denture cleaning method. The purpose of this study was to evaluate the abrasiveness of specific and non-specific denture cleaning dentifrices on different heat-polymerized acrylic resins. Sixteen specimens $(90 \times 30 \times 3 \mathrm{~mm})$ of each acrylic resin (QC-20, Lucitone 550, Clássico, Vipi-Cril) were prepared and randomly assigned to 4 groups: 1: control (distilled water), 2: Colgate, 3: Bonyplus and 4: Dentu-Creme. The specimens were subjected to simulated toothbrushing in an automatic brushing machine using 35,600 brush strokes for each specimen. Brushing abrasion run at a 200-g load with the specimens immersed in 2:1 dentifrice/water slurry. Specimens were reconditioned to constant mass and the mass loss (mg) was evaluated. Data were analyzed by 2 -way ANOVA and Tukey's test $(\alpha=0.05)$. Analysis of dentifrices' abrasive particles was made by scanning electron microscopy. Colgate produced the greatest mass reduction (42.44 mg, $\mathrm{p}<0.05)$, followed by Dentu-Creme (33.60 mg). Bonyplus was the less abrasive $(19.91 \mathrm{mg})$, similar to the control group (19.69 mg) (p>0.05). The mass loss values indicated that QC-20 $(33.13 \mathrm{mg})$ and Lucitone $550(33.05 \mathrm{mg})$ resins were less $(\mathrm{p}<0.05)$ resistant to abrasion than Clássico $(26.04 \mathrm{mg})$ and Vipi-Cril $(23.43 \mathrm{mg})$. In conclusion, Colgate produced the greatest abrasion. Specific dentifrices for dentures tend to cause less damage to acrylic resins.
\end{abstract}

Key words: Acrylic resins. Brushing. Dentifrice. Abrasion.

\section{INTRODUCTION}

Biofilm accumulation on the surfaces of dentures is a common problem among denture wearers ${ }^{9,18,24}$. Some studies have shown that colonization of denture inner surfaces by yeasts causes oral and systemic disease ${ }^{11,23}$, particularly in aged and immunodepressed patients and those with reduced salivary flow ${ }^{11,26}$. It has been demonstrated association between biofilm and denture-induced stomatitis ${ }^{1-3,5,6}$. Thus, correct denture cleansing is essential in preventing oral diseases among edentulous patients.

The mechanical removal of debris with the use of toothbrush, dentifrice and water is a popular cleansing technique used by great part of denture wearers ${ }^{7}$. Although it is a simple, inexpensive and effective method ${ }^{10,25}$, a major disadvantage is that the abrasive action could result in wear of the denture base and relining materials ${ }^{10,12}$.

Abrasion caused by brushing of acrylic resin denture bases polymerized by different methods may result in mass loss, surface roughness, loss of surface polishing, problems on denture adaptation due the loss of surface details and difficulty on the maintenance of denture hygiene , $^{7,22,27}$. Irregularities on acrylic resin surface favor biofilm formation and pigmentation ${ }^{16,20,28,29}$. The critical threshold surface roughness for bacterial adhesion is $0.2 \mu \mathrm{m}^{30}$ and the acceptable mass loss of acrylic resins is still unknown.

Dentifrices usually have a complex composition, varying among different brands. The main components are: water, detergent, thickening agent and specific coloring, flavoring and abrasive agents ${ }^{13,15}$. The most commonly used abrasives in dentifrices are silica and calcium carbonate. Most in vitro studies employ motor-driven brushing machines, in order 
to standardize time, speed, frequency of brush strokes, applied load and amount of dentifrice ${ }^{19,28}$. The methods used for measurement of abrasion include mass loss, luster changes, surface roughness, microscopic examination and radiometric technique.

Investigating the abrasion resistance of different denture resins together with the abrasiveness of different dentifrices is of clinical interest to help selecting the most appropriate materials and methods for denture cleansing with no significant damage to the denture base. The aim of this study was to evaluate the mass loss of four commercially available heat-polymerized acrylic resins after simulated toothbrushing with three different dentifrices. The tested null hypothesis was that different denture resins and dentifrices produce different mass loss after toothbrushing.

\section{MATERIALS AND METHODS}

The acrylic resins and dentifrices used in this study are presented in Tables 1 and 2, respectively. These products were selected as being representative of those available on the market.

Sixteen specimens of each acrylic resin were fabricated using a stone mold. Plexiglas patterns $(90 \times 30 \times 3 \mathrm{~mm})$ were included into investment flasks (No. 6 Jon, Jon, São Paulo, SP, Brazil) to allow reproduction of specimens by conventional dental procedures. The acrylic resins were mixed following the manufacturer's instructions and inserted into the mold. After polymerization, the specimens were bench cooled at room temperature before being removed from the mold and were thereafter carefully finished, polished and immersed in water at $37^{\circ} \mathrm{C}$ for 7 days until use ${ }^{17}$. The specimens were designed to fit on the custom-made metal plate of the brushing machine.

The specimens of all acrylic resins were allocated to 4 groups $(n=4)$. In group 1 , (control), the specimens were brushed with distilled water; in group 2, the specimens were brushed with a dentifrice indicated for natural teeth (Colgate); in groups 3 and 4, the specimens were brushed with dentifrices specific for complete dentures (Bonyplus and Dentu-Creme, respectively).

Prior to simulated toothbrushing, the specimens were removed from the water bath, rinsed with tap water, cleaned for $1 \mathrm{~min}$ in an ultrasonic bath with deionized water containing $1 \%$ of detergent (Limpol neutral, Bombril S/A, São Bernardo do Campo, Brazil), dried with absorbent paper and weighed in an analytical balance accurate to $0.1 \mathrm{mg}$ after $1 \mathrm{~min}$ (Metler Toledo $\mathrm{GMbH}$, Laboratory \& Weighing Technologies, Greifensee, Switzerland).

The specimens were positioned in the specimen holder containing the slurry bath in the mechanical cross-brushing machine (Precision Shop, University of São Paulo, Ribeirão Preto, São Paulo, Brazil) equipped with 6 soft nylon-bristled toothbrushes (Tek, Soft, Johnson \& Johnson), in such a way that 6 specimens could be brushed simultaneously. The specimens were subjected to a linear toothbrush abrasion movement with a rate of 356 brush strokes (forth and back)

TABLE 1- Specifications of the tested heat-polymerized acrylic resins

Commercial Manufacturer/City/Country Composition
Brand

Lucitone 550

Dentsply Ind. Com. Ltd

Petrópolis, RJ, Brazil

QC-20

Dentsply Ind. Com. Ltd

Petrópolis, RJ, Brazil

Clássico

Artigos Odontológicos Clássico Ltd São Paulo, SP, Brazil

Vipi Cril

Dental Vipi Ltd

Pirassununga, SP, Brazil
Polymer powder: copolymer (methyl-n-butyl) methacrylate, benzoyl peroxide.

Monomer Liquid: methyl methacrylate, ethylene glycol dimethacrylate, hydroquinone.

Polymer powder: copolymer (methyl-n-butyl) methacrylate, benzoyl peroxide.

Monomer Liquid: methyl methacrylate, ethylene glycol dimethacrylate, hydroquinone, terpinolene, N-dimethyl-ptoluidine.

Polymer powder: copolymer (methyl-n-butyl) methacrylate, benzoyl peroxide.

Monomer Liquid: methyl methacrylate, ethylene glycol dimethacrylate, hydroquinone.

Polymer powder: copolymer (methyl-n-butyl) methacrylate, benzoyl peroxide.

Monomer Liquid: methyl methacrylate, ethylene glycol dimethacrylate, hydroquinone. 
TABLE 2- Characteristics of tested dentifrices

\begin{tabular}{lccc}
\hline Dentifrice & Manufacturer & Abrasive particles & Indication \\
\hline Colgate com cálcio & $\begin{array}{c}\text { Colgate-Palmolive, Divisão da } \\
\text { Kolynos do Brasil, Osasco, SP, } \\
\text { Brazil }\end{array}$ & Calcium carbonate & Natural teeth \\
Bonyplus & Bonyf AG, Vaduz, Liechtenstein & None & Complete dentures \\
Dentu-creme & Block Drug Company Inc., Jersey & Calcium carbonate & Complete dentures \\
\hline
\end{tabular}

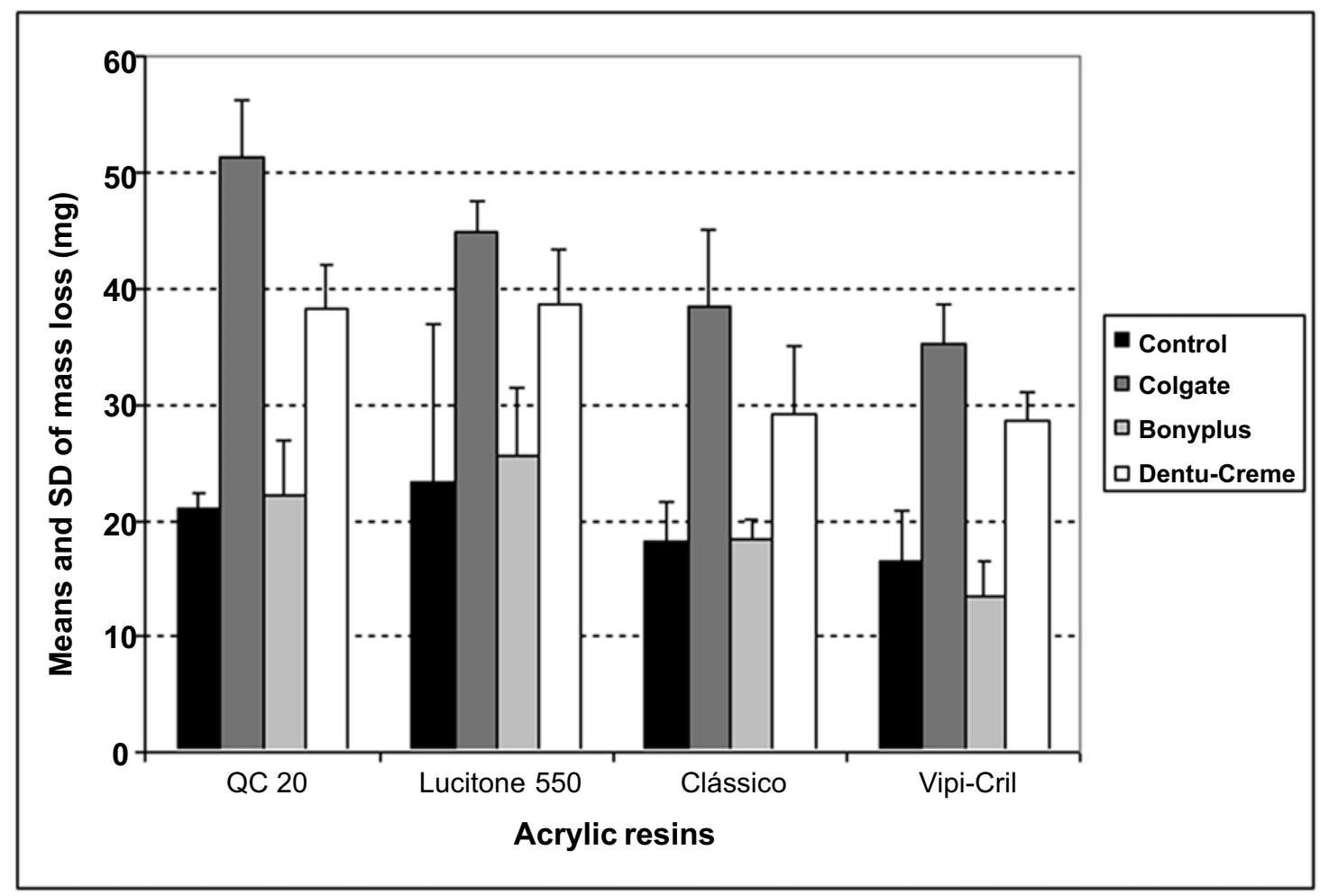

FIGURE 1- Means and SD of mass loss $(\mathrm{mg})$ of the tested acrylic resin after dentifrice use

per minute, totalizing 35,600 brush strokes for each specimen, which is representative of 2 years of denture cleansing ${ }^{13}$. The machine was set to provide $200 \mathrm{~g}$ vertical load over each specimen and a $3.8 \mathrm{~cm}$ toothbrush trail. Brushing was carried out in the presence of a dentifrice/distilled water slurry (2:1; $\mathrm{w} / \mathrm{w})$, which was placed into the slurry bath ${ }^{17}$. A stainless steel agitating fin was fastened to the end of the brush to ensure adequate mixing, so that settling of the abrasive material would be minimized during brushing.

After brushing, the specimens were removed from the specimen holder, rinsed thoroughly and blot dried with soft absorbent paper. Each specimen was weighed in the analytical balance as previously described. Mass loss due to wear was calculated as the difference between the mass of each specimen before and after brushing.

The results of mass loss were subjected to 2-way ANOVA and Tukey's test $(\alpha=0.05)$ to examine the influence of materials and groups.

\section{RESULTS}

Figure 1 shows the means and standard deviation (SD) of the mass loss $(\mathrm{mg})$ of the tested acrylic resins after toothbrushing.

The results of ANOVA are presented on Table 3 . According to the Tukey's test for mass loss (mg) of acrylic resins and dentifrices, the resins QC-20 and Lucitone 550 showed greater mass reduction, which indicated lower abrasion resistance as compared to the other resins. Colgate was the most abrasive dentifrice, followed by Dentu-Creme and Bonyplus (Tables 4 and 5). 
TABLE 3- ANOVA results for mass loss of acrylic resins

\begin{tabular}{|c|c|c|c|c|c|}
\hline & df & ss & $\mathbf{v}$ & $\mathbf{F}$ & \\
\hline $\mathrm{D}$ & 5935.9453 & 3 & 1978.6484 & 69.85 & $\bullet$ \\
\hline $\mathrm{R}$ & 1171.8828 & 3 & 390.6276 & 13.79 & $\bullet$ \\
\hline DxR & 231.0508 & 9 & 25.6723 & 0.91 & ns \\
\hline Residuals & 1359.7305 & 48 & 28.3277 & & \\
\hline Total variation & 8698.6094 & 63 & & & \\
\hline
\end{tabular}

D: dentifrices; R: acrylic resins; $\quad$ : P $<0.05 ; \quad$ ns: non-significant.

TABLE 4- Means of mass loss promoted by each dentifice on the acrylic resins evaluated in this study

\begin{tabular}{lccc}
\hline Colgate & Dentu-Creme & Bonyplus & Control \\
\hline $42.438^{\mathrm{a}}$ & $33.600^{\mathrm{b}}$ & $19.906^{\mathrm{c}}$ & $19.694^{\mathrm{c}}$ \\
\hline
\end{tabular}

Different letters indicate statistically significant difference $(p<0.05)$.

\section{DISCUSSION}

Since dentifrice and toothbrush association is one of the most common methods for oral hygiene, it should promote good cleansing with minimal damage to teeth, gingival tissues and restorative and prosthetic materials. It is thus important to evaluate the abrasion resistance to brushing of heat-polymerized acrylic resins used for fabrication of denture bases. The acrylic resin hardness, the type of abrasive agent and its concentration, the dimension and form of abrasive particles, the toothbrush and the load applied are some of the different factors that influence the abrasion of acrylic resin by brushing , $^{4,12}$.

Colgate and Dentu-Creme dentifrices use calcium carbonate as abrasive particles. In the present study, the results showed that Colgate was significantly more abrasive than Dentu-Creme (Table 4), as reported by Freitas and Paranhos (2006) ${ }^{10}$. This previous study ${ }^{10}$ also showed, by microscopic analysis, that Colgate's abrasive particles presented an irregular spherical form, irregular size and heterogeneous distribution, while Dentu-Creme's abrasive particles presented a regular form, small size and homogeneous distribution. This confirms the importance of the abrasive agent's particles form, size and distribution on the abrasive capacity of dentifrices ${ }^{4,12}$.

Some abrasion is necessary for stain removal. The present study did not analyze this topic. Many variables must be considered in the fabrication of dentifrice for cleansing and polishing: acrylic porosity, hardness, size and surface configuration of the cleansing agent, the type of compounds for polishing used along with the cleansing agent, and the hardness of the cleansing and polishing agent ${ }^{20}$.

Some studies have demonstrated the importance of
TABLE 5- Means of mass loss of each acrylic resin promoted by the dentifrices used in this study

\begin{tabular}{cccc}
\hline QC-20 & Lucitone 550 & Clássico & Vipi-Cril \\
\hline $33.125^{\mathrm{a}}$ & $33.050^{\mathrm{a}}$ & $26.037^{\mathrm{b}}$ & $23.425^{\mathrm{b}}$ \\
\hline $\begin{array}{l}\text { Different letters indicate statistically significant difference } \\
(p<0.05) .\end{array}$
\end{tabular}

dentifrice abrasiveness on promoting an efficient cleansing because brushing with water alone does not remove stains and organic deposits from dentures ${ }^{13,14}$. Furthermore, lowabrasion dentifrices do not remove stains from smoker's dentures either ${ }^{22}$. Therefore, abrasion is an important issue to be considered when selecting a dentifrice. It should be abrasive enough to maintain the denture clean ${ }^{15}$.

A soft-bristle toothbrush was used in the present study because it is cheap and has good quality, being therefore accessible to most patients. Brushing with distilled water caused minimum mass reduction, confirming the results from other studies ${ }^{28}$. Bonyplus has no abrasive particles and its results were statistically similar to the control group.

The purpose of this study was to compare dentifrices under the same experimental conditions. Each specimen was subjected to 35,600 brush strokes, and the load applied on each brush head was $200 \mathrm{~g}$, which was estimated to be equivalent to 2 years of manual brushing ${ }^{28}$. Correlation between in vitro tests and clinical reality is difficult. Artificial brushing is vigorous and may be more abrasive than manual brushing $^{19}$, but some works have shown similar results between laboratory and clinical experiments ${ }^{20,21}$. Resin characteristics, such as monomer/polymer ratio, presence of cross-linking agents, mixture uniformity, polymerization cycle, cooling rate, specimen thickness and surface finishing may influence the interaction between specimens and dentifrices. It is therefore necessary to standardize these variables as carefully as possible ${ }^{13}$.

There is some divergence regarding the use of gravimetric method for abrasion measurement. Mass reduction is approved by the ISO/TC $106(1996)^{17}$ specification as an abrasion indicator and it is the simplest method of producing values for abrasion of acrylic resins ${ }^{25}$. 
Due to the experimental conditions of this study, mass reduction was analyzed to assess abrasion. Sexson and Phillips $^{27}$ showed that mass reduction obtained from brushing rotating acrylic resin specimens was similar to that produced when specimens were allowed to remain stationary, although microscopic examination revealed that the rotating specimens had different surface topography. Hence, surface roughness and brightness loss would not provide results valid for this study, in which the specimens remained stationary.

During the brushing procedure, the specimens were kept immersed in dentifrice slurry for $100 \mathrm{~min}$ and some water sorption could occur. For this reason, the specimens were stored in water at $37^{\circ} \mathrm{C}$ for 7 days before the test in order to balance water sorption ${ }^{17}$.

When submitted to cycles at higher temperature, heatpolymerized acrylic resins have been shown to produce specimens with higher abrasion resistance ${ }^{25,28}$. Haselden, et al. ${ }^{12}$ verified that the effects of Colgate and Dentu-Creme dentifrices differed according to the resins used and ranking order was unpredictable. In this study, Colgate was more abrasive than Dentu-Creme for all specimens. Hence, the ranking order was the same for all acrylic resin brands. QC20 and Lucitone 550 resins showed greater mass reduction as compared to the other resins when submitted to brushing associated to dentifrice (Table 5). These were unexpected results because all the resin groups had similar polymerization cycles.

An important question concerns the clinical relevance of the abrasion produced by dentifrices on dentures. Facq and Volpe ${ }^{8}$ concluded that the abrasion of dentifrices on veneer crowns was clinically insignificant. Murray, et al. ${ }^{22}$ stated that it is possible to estimate that twice daily brushing for 2 min with a dentifrice containing calcium carbonate would result in the removal of $25 \mathrm{im}$ of resin surface per year. Therefore, further studies similar to the present one are required to determine the impact of the wear produced by dentifrices on dentures. In vitro experiments are usually helpful to compare the relative effectiveness of denture cleansers and to develop an understanding of the acting mode of each denture cleanser ${ }^{23}$. In addition, the present study provides more details concerning the performance of some acrylic resins under abrasive load. It might help dentists indicating cleansers for denture wearers.

\section{CONCLUSION}

Based on the obtained results and within the limitations of an in vitro study, it may be concluded that differences exist among heat-polymerized acrylic resins concerning abrasion resistance and that dentifrices specific for denture cleansing tend to cause less damage to acrylic resin surface.

\section{REFERENCES}

1- Andruciolli MCD, Macedo LD, Panzeri H, Lara EHG, Paranhos HFO. Comparison of two pastes for the removal of biofilm from dentures and palatal lesions in patients with atrophic chronic candidiasis. Braz Dent J. 2004;15(3):220-4

2- Barbeau J, Séguin J, Goulet JP, Koninck L, Avon SL, Lalonde B, et al. Reassessing the presence of Candida albicans in denture related stomatitis. Oral Surg Oral Med Oral Pathol Oral Radiol Endod. 2003;95(1):51-9.

3- Barnabé W, Mendonça T Neto, Pimenta FC, Pegoraro LF, Scolaro JM. Efficacy of sodium hypochlorite and coconut soap used as disinfecting agents in the reduction of denture stomatitis, Streptococcus mutans and Candida albicans. J Oral Rehabil. 2004;31(5):453-9.

4- Camargo IMC, Saiki M, Vasconcellos MBA, Ávila DM. Abrasiveness evaluation of silica and calcium carbonate used in the production of dentifrices. J Cosmet Sci. 2001;52:163-7.

5- Coelho CM, Souza YT, Dare AM. Denture-related oral mucosal lesions in a Brazilian school of dentistry. J Oral Rehabil. 2004;31(2):135-9.

6- Dhir G, Berzins DW, Dhuru VB, Periaathamby AR, Dentino A. Physical properties of denture base resins potentially resistant to Candida adhesion. J Prosthodont. 2007;16(6):465-72

7- Dyer D, Macdonald E, Newcombe RG, Scratcher C, Ley F, Addy M. Abrasion and stain removal by different manual toothbrushes and brush actions: studies in vitro. J Clin Periodontol. 2001;28:121-7.

8- Facq JM, Volpe AR. In vivo actual abrasiveness of three dentifrices against acrylic surfaces of veneer crowns. J Am Dent Assoc. 1970;80:31723.

9- Fernandes RAG, Silva-Lovato CH, Paranhos HFO, Ito IY. Efficacy of three denture brushes on biofilm removal from complete dentures. J Appl Oral Sci. 2007;15(1):39-43.

10- Freitas KM, Paranhos HFO. Weight loss of five commercially available denture teeth after toothbrushing with three different dentifrices. J Appl Oral Sci. 2006;14(4):242-6.

11- Gornitsky M, Paradis I, Landaverde G, Mallo AM, Velly AM. A clinical and microbiological evaluation of denture cleansers for geriatric patients in long term care institutions. J Can Dent Assoc. 2002;68(1):39-45.

12- Haselden CA, Hobkirk JA, Pearson GJ, Davies EHA. Comparison between the wear resistance of three types of denture resin to three different dentifrices. J Oral Rehabil. 1998; 25:335-9.

13- Heath JR, Wilson HJ. The effect of dentifrices on restorative materials. J Oral Rehabil. 1974;1:47-54

14- Heath JR, Davenport JC, Jones PA. The abrasion of acrylic resin by cleaning pastes. J Oral Rehabil. 1983;10:159-75.

15- Hembre ME, Hembre JH. Relative abrasiveness of dentifrices. Dent Hyg. 1977;51:253-55.

16- Hirano S, May KB, Wagner WC, Hacker CH. In vitro wear of resin denture teeth. J Prosthet Dent. 1998;79:152-5.

17- International Organization for Standardization. Technical specification 14569-1. Dental Materials - Guidance on testing of wear resistance Part 1: wear by tooth brushing. Switzerland, ISO; 1996.

18- Keng SB, Lim M. Denture plaque distribution and effectiveness of a perborate-containing denture cleanser. Quintessence Int. 1996;24(5):3415 . 
19- Manly RS, Wiren J, Manly PJ, Keene RC. A method for measurement of abrasion of dentin by toothbrush and dentifrice. J Dent Res. $1965 ; 44: 533-40$

20- Muhler ID, Stookey GK, Hassel TM. The development and evaluation of an improved denture cleaning and polishing paste. J Indiana State Dent Assoc. 1969;48:17-27.

21- Murray ID, McCabe JF, Storer R. Abrasivity of denture cleaning pastes "in vitro" and "in situ”. Br Dent J. 1986;161:137-41.

22- Murray ID, McCabe JF, Storer R. The relationship between the abrasivity and cleaning power of the dentifrice-type denture cleaners. $\mathrm{Br}$ Dent J. 1986;161:205-12.

23- Nikawa H, Hamada T, Yamashiro H, Kumagai H. A review of in vitro and in vivo methods to evaluate the efficacy of denture cleansers. Int $\mathrm{J}$ Prosthod. 1999;12:153-9.

24- Paranhos HFO, Silva-Lovato $\mathrm{CH}$, Venezian GV, Macedo LD, Souza RF. Distribution of biofilm on internal and external surfaces of upper complete dentures: the effect of hygiene instruction. Gerodontology. 2007;24(3):162-8

25- Purnaveja S, Fletcher AM, Ritchie GM, Amin WM, Moradians S, Dodd AW. Compatibility of denture cleansers with some new self-curing denture base materials. Biomaterials. 1982;3:251-2.

26- Salles AES, Macedo LD, Fernandes RAG, Silva-Lovato CH, Paranhos HFO. Comparative analysis of biofilm levels in complete upper and lower dentures after brushing associated with specific denture paste and neutral soap. Gerodontology. 2007;24(4):217-23

27- Sexson JS, Phillips RW. Studies on the effects of abrasives on acrylic resins. J Prosthet Dent. 1951;1:454-71.

28- Vieira DF, Phillips RW. Influence of certain variables on the abrasion of acrylic resin veneering materials. J Prosthet Dent.1962;12:720-31.

29- Wictorin L. Effect of toothbrushing on acrylic resin veneering material. II Abrasive effect of selected dentifrices and toothbrushes. Acta Odont Scand. 1972;30(3):383-95.

30- Yap AU, Wu SS, Chelvan S, Tan ES. Effect of hygiene maintenance procedures on surface roughness of composite restoratives. Oper Dent. 2005;30(1):99-104 